\title{
Crystallization Behavior of M97 Series Silicone Cushions
}

A. Chien, S. DeTeresa, R. Cohenour, J. Schneider, J. LeMay, B. Balazs

\section{September 7, 2000}

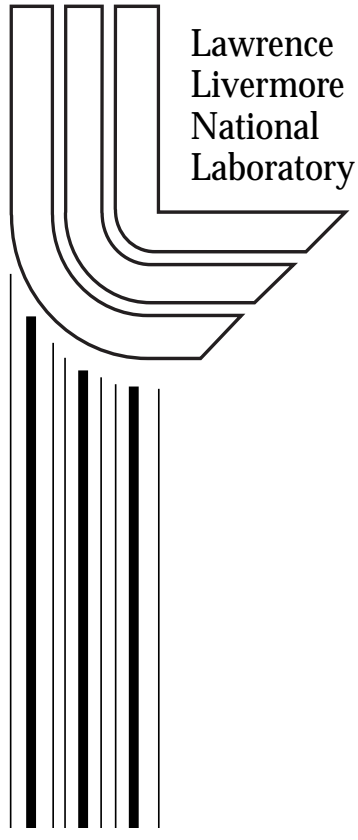




\section{DISCLAIMER}

This document was prepared as an account of work sponsored by an agency of the United States Government. Neither the United States Government nor the University of California nor any of their employees, makes any warranty, express or implied, or assumes any legal liability or responsibility for the accuracy, completeness, or usefulness of any information, apparatus, product, or process disclosed, or represents that its use would not infringe privately owned rights. Reference herein to any specific commercial product, process, or service by trade name, trademark, manufacturer, or otherwise, does not necessarily constitute or imply its endorsement, recommendation, or favoring by the United States Government or the University of California. The views and opinions of authors expressed herein do not necessarily state or reflect those of the United States Government or the University of California, and shall not be used for advertising or product endorsement purposes.

This work was performed under the auspices of the U. S. Department of Energy by the University of California, Lawrence Livermore National Laboratory under Contract No. W-7405-Eng-48.

This report has been reproduced directly from the best available copy.

Available to DOE and DOE contractors from the

Office of Scientific and Technical Information

P.O. Box 62, Oak Ridge, TN 37831

Prices available from (423) 576-8401

http://apollo.osti.gov/bridge/

Available to the public from the National Technical Information Service

U.S. Department of Commerce 5285 Port Royal Rd., Springfield, VA 22161

http://www.ntis.gov/

OR

Lawrence Livermore National Laboratory Technical Information Department's Digital Library http://www.llnl.gov/tid/Library.html 


\title{
Crystallization Behavior of M97 Series Silicone Cushions
}

\author{
Allen Chien $^{1}$, Steve DeTeresa ${ }^{2}$, Rebecca Cohenour $^{3}$, Jim SchneideR ${ }^{3}$ \\ JAMES LEMAY ${ }^{1}$, AND BRYAN BALAZS ${ }^{1}$ \\ ${ }^{1}$ Chemistry and Materials Science Directorate \\ 2ENGINEERING DIRECTORATE \\ LAWRENCE LiVERMORE NATIONAL LABORATORY, LiVERMORE, CA 94551 \\ ${ }^{3}$ HONEYWELL INC. \\ Federal Manufacturing \& Technologies, Kansas City, MO 64141
}

\begin{abstract}
M97 series siloxanes are poly(dimethyl-diphenyl) siloxanes that are reinforced through a mixture of precipitated and fumed silica fillers which are blended in through the addition of a short chain polydimethylsiloxane processing aid. M97 silicones exhibit crystallization at $-80^{\circ} \mathrm{C}$ by thermal (modulated differential scanning calorimetry) and mechanical (dynamic mechanical analysis) techniques. Isothermal dynamic mechanical analysis experiments illustrated that crystallization occurred over a 1.8 hour period in silicafilled systems and 2.8 hours in unfilled systems. The onset of crystallization typically occurred after a 30 minute incubation/nucleation period. $\boldsymbol{\gamma}$-radiation caused the crystallization rate to decrease proportionally with dosage, but did not decrease the amount of crystallization that ultimately occurred. Irradiation in vacuum resulted in slower overall crystallization rates compared to air irradiation due to increased crosslinking of the polymer matrix under vacuum. Modulated differential scanning calorimetry contrasted the crystallization and melting behavior of pure PDMS versus the M97 base polymer and helped determine which component of the composite was the origin of the crystallization phenomena.
\end{abstract}

\section{INTRODUCTION}

The crystallization of polymers depends upon several factors including symmetry, chain flexibility, side groups, branching, tacticity, and molecular weight (MW). ${ }^{1}$ Polydimethylsiloxane (PDMS) is known to exhibit cold crystallization at temperatures $\left(\mathrm{T}_{\mathrm{CC}}\right)$ of $-70^{\circ} \mathrm{C}$ to $-100^{\circ} \mathrm{C}$ based upon differential scanning calorimetry (DSC) and x-ray diffraction (XRD) studies. ${ }^{2,3,4}$ Cold crystallization is crystallization that occurs during the heating of a polymer that had been previously cooled so rapidly that crystallization could not occur to its full extent. In DSC analysis, cold crystallization is usually observed by an exothermic peak in which the size and position $\left(\mathrm{T}_{\mathrm{cc}}\right)$ of the peak are determined by features such as temperature ramp rates, molecular weight of the polymer, filler content, and crosslinked-induced changes in the mobility of the polymer. XRD analysis has been used to determine quantitative amounts of crystallinity in PDMS by comparing the relative intensities of amorphous and crystalline peaks.

Aranguren ${ }^{3}$ demonstrated that, for PDMS cooled at increasingly slower rates, $\mathrm{T}_{\mathrm{CC}}$ shifts to higher temperatures and decreases in magnitude, with cold crystallization no longer being observable at cooling rates of less than $1.5^{\circ} \mathrm{C} / \mathrm{min}$. However, for smaller molecular weight chains, crystallization occurs at lower temperatures due to the smaller chains having higher mobilities allowing for larger and more ordered crystals to be formed. With the addition of fillers such as silica, $\mathrm{T}_{\mathrm{C} C}$ and crystallization rates 
have been shown to increase, presumably due to ordering of the polymer on the surface of the filler phase providing heterogeneous nucleation sites for crystallization. The amount of crystallization has also been demonstrated to decrease due to adsorption of the polymer on the filler surface constraining the motion of the polymer and therefore reducing its ability to crystallize. At a silica loading of $10 \mathrm{wt}$. \% or higher in the PDMS system, cold crystallization was no longer observable by DSC analyses.

The addition of phenyl side groups to PDMS has been shown to reduce the rate and extent of crystallization of the copolymer compared to that of pure PDMS.5,6 The M97 series materials considered here are a random block copolymer of dimethyl, diphenyl, and methylvinyl siloxanes in 90.7 wt. $\%, 9$ wt. $\%$ and 0.31 wt. \% amounts $(88.5 \mathrm{~mol}$ \% PDMS, 11.2 mol. \% PDPS, and $0.3 \mathrm{~mol}$. \% PMVS), respectively. Chistov et al. showed that for poly(dimethylmethylphenyl)siloxane, crystallization is observable by DSC up to $6.5 \mathrm{~mol} \%$ phenyl composition. ${ }^{5}$ However, Andrianov et al. demonstrated that crystallization was detected for compositions up to $8 \mathrm{~mol} \%$ phenyl for poly(dimethyldiphenyl) siloxane (PDMDPS) by XRD. ${ }^{6}$ Discrepancies between the two studies could be due to differences in polymer structure, molecular weights, and instrument ramp rates. Crystallization rates were also observed to decrease with increasing amounts of phenyl monomer due to interruption in the polymer main chain regularity and a reduction in chain flexibility.

The effects of $\gamma$-radiation on crosslinking of PDMDPS copolymers has been examined by solvent swelling, viscometry, and light scattering. ${ }^{7,}, 8,9,10$ Phenyl groups have been shown to provide protective effects against crosslinking due to the ability of the resonant structure of the phenyl group to mitigate the radiative energy. Individual phenyl groups have been ascribed as protecting 5-6 neighboring units in the main chain at low phenyl ( $<10 \mathrm{~mol} \%)$ concentrations with a reduction to only 2-3 neighbors at much higher concentrations (40 mol \%). In previous work, we detailed the effects of gamma radiation on crosslink density by solvent swelling ${ }^{7}$. A modified solvent swelling technique was used to resolve the separate contributions of the matrix polymer and filler phase to the overall apparent crosslink density and showed that hydrogen bonding at the polymerfiller interface dominates the overall apparent crosslink density of the material. Samples irradiated in air displayed decreased hydrogen bonding at the polymer-filler interface, while vacuum irradiation revealed the opposite effect. The polymer matrix showed little change in crosslink density at low doses (i.e., 0-5 Mrad) in air, but underwent a gradual increase at higher doses. Vacuum irradiated samples increased in crosslink density at lower doses ( $<1 \mathrm{Mrad}$ ) and to a much greater extent than those samples irradiated in air. Presumably, the lack of oxygen either: a) prolongs the lifetime of radical species formed during irradiation thus enhancing opportunities for crosslinks to form, or b) precludes the formation of peroxide or hyperperoxide species which might otherwise be involved in chain scission reactions. ${ }^{11}$

The purpose of the current work is to examine the crystallization behavior of unfilled and silica-filled M97 series siloxane polymer systems. The extent of crystallization and the crystallization rates were probed using DMA, modulated DSC and XRD. Results will show that at high (11 mol \%) diphenyl content, these polymers still exhibit crystallization, but that the initiation of crystallization is dramatically slower relative to that of pure PDMS.

\section{EXPERIMENTAL}

The random block copolymer examined in this study consisted of dimethyl (DMS), diphenyl (DPS), and methyl vinyl (MVS) siloxane monomer units. The percentages of each monomer unit in the base rubber were 90.7 wt. \% DMS, 9.0 wt. \% DPS, and 0.31 wt. \% MVS (NuSil Corp., 
Carpenteria, CA). The polymer was compounded with silica by milling with a mixture of 21.6 wt. \% fumed silica (Cab-oSil M7D, Cabot Corporation, Tuscola, Il), 4.0 wt. \% precipitated silica (Hi-Sil 233, PPG Industries Inc., Pittsburgh, Pa), and 6.8 wt. \% ethoxy-endblocked siloxane processing aid (Y1587, Union Carbide Corp, Danbury, CT). The resulting filledpolymer system was studied in two forms: a fully dense form and a $50 \%$ porous open cell material. The porous samples were formed by milling the reinforced gum with 50 volume percent of $25-40$ mesh prilled urea spheres (Coastal Chem. Inc. Cheyenne, Wyoming), which were subsubsequently washed out with water after crosslinking of the polymer. After aging at 3 weeks at room temperature, both the unfilled and silica-filled polymer gums were crosslinked with the application of heat to activate the peroxide curing agent included in the base gum.

The presence of pores in the cellular system did not have any effect on the crystallization behavior of the material, and this filled porous system was the one studied unless otherwise indicated. Samples were irradiated for various periods of time in a stainless steel container (volume $\sim 2 l$ ) exposed to a ${ }^{60} \mathrm{Co}$ gamma source $\left(\mathrm{E}_{\mathrm{avg}} \sim 1.2 \mathrm{MeV}, \quad 0.5\right.$ $\mathrm{Mrad} / \mathrm{hr}$ ). Vacuum samples were encapsulated in evacuated glass tubes (pressure $\sim 1 \times 10^{-4}$ torr), while airirradiated samples were left exposed to the air environment inside the container. All experiments were performed at the same dose rate.

DMA testing was performed (Rheometrics RMS-800 Dynamic Mechanical Spectrometer, Piscataway, $\mathrm{NJ})$ in parallel plate geometry with a static compression force of $400 \mathrm{~g}$. Specimens were disks $1 \mathrm{~mm}$ in thickness and $13 \mathrm{~mm}$ in diameter. The sample was sheared at a frequency of $f=6.3 \mathrm{rad} / \mathrm{sec}$ and using a ramp sequence of $20^{\circ} \mathrm{C}$ from $-150^{\circ} \mathrm{C}$ to $20^{\circ} \mathrm{C}$ at a rate of $2^{\circ} \mathrm{C} / \mathrm{min}$. The maximum strain placed upon the sample was $0.5 \%$. Isothermal DMA runs were performed by cooling the sample down to $-83^{\circ} \mathrm{C}$ and dwelling at this temperature for times ranging from 2 to 10 hours.

DSC analyses were performed (TA Instruments, MDSC 2920, New Castle, $\mathrm{DE})$ by cooling the sample at a rate of $6^{\circ} \mathrm{C} / \mathrm{min}$. to $-150^{\circ} \mathrm{C}$ from room temperature. Heating of the samples was then performed at $3{ }^{\circ} \mathrm{C} / \mathrm{min}$. with a modulation frequency of $\sim 0.04^{\circ} \mathrm{C} / 50 \mathrm{sec}$. Some DSC samples were analyzed with the addition of an isothermal dwell of up to 2 hours at $-83^{\circ} \mathrm{C}$ on the cool down cycle prior to commencing the rest of the run.

\section{RESULTS AND Discussion}

Results of DMA and MDSC analyses show that cold crystallization took place in filled M97 at -75 to $-80^{\circ} \mathrm{C}$. Figure 1 illustrates the thermal behavior of M97 samples as measured by DSC. The glass transition temperature $\left(\mathrm{T}_{\mathrm{G}}\right)$ was observed to occur at $-120^{\circ} \mathrm{C}$ while melting $\left(\mathrm{T}_{\mathrm{M}}\right)$ was detected by an endothermic peak at $-60^{\circ} \mathrm{C}$ $\left(\Delta \mathrm{H}_{\mathrm{M}} \sim-2.5 \mathrm{~J} / \mathrm{g}\right)$. Crystallization was determined by the presence of an exothermic peak at $-80^{\circ} \mathrm{C}$ with a heat of cold crystallization $\left(\Delta \mathrm{H}_{\mathrm{c}}\right)$ of $\sim 1.5 \mathrm{~J} / \mathrm{g}$.

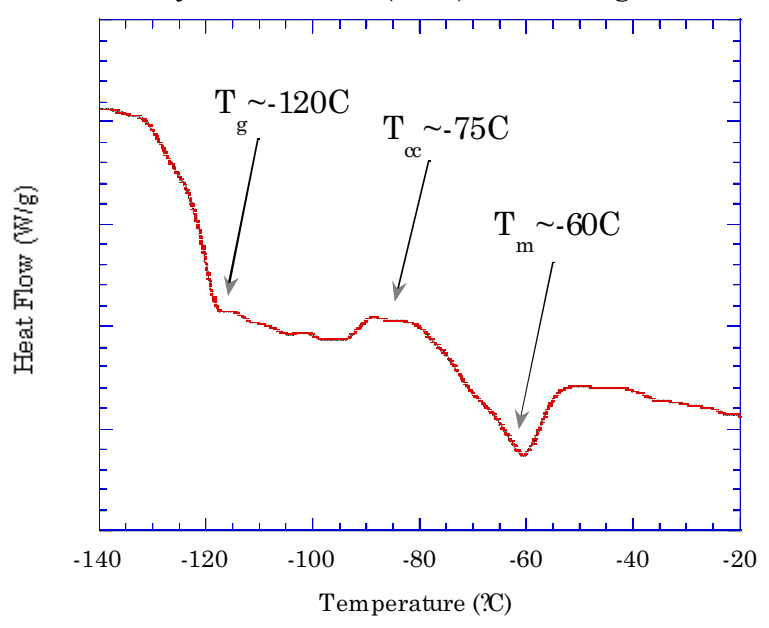

FIGURE 1. DSC of M97 composite showing the glass transition, cold crystallization, and melting events.

The amount of crystallization in this polymer is very small compared to that of pure PDMS (MW=150,000) shown in Fig. 2 , which exhibited an $\Delta \mathrm{H}_{\mathrm{C}}$ of $19 \mathrm{~J} / \mathrm{g}$ at $96^{\circ} \mathrm{C}$ under the same conditions. This 
indicates that, as expected, the phenyl side groups and random nature of this copolymer act as an effective barrier to extensive crystallization. Figure 3 shows a typical plot of storage modulus ( $\left.G^{\prime}\right)$, loss modulus (G"), and loss tangent $(\tan \delta)$ vs. temperature for M97. The glass transition is evidenced by the drop in G' and peak in $\tan \delta$ at $-120^{\circ} \mathrm{C}$ and cold crystallization is also evidenced by the peak in $\mathrm{G}^{\prime}$ at $-75^{\circ} \mathrm{C}$ where the formation and melting of the crystalline phase are the cause of the shear modulus increase.

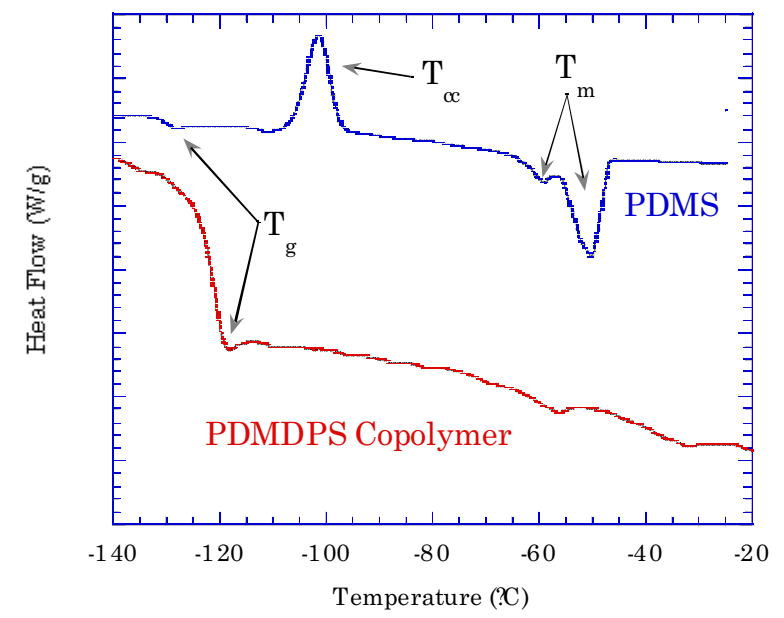

Figure 2. DSC of PDMS and M97 base polymer (PDMDPS).

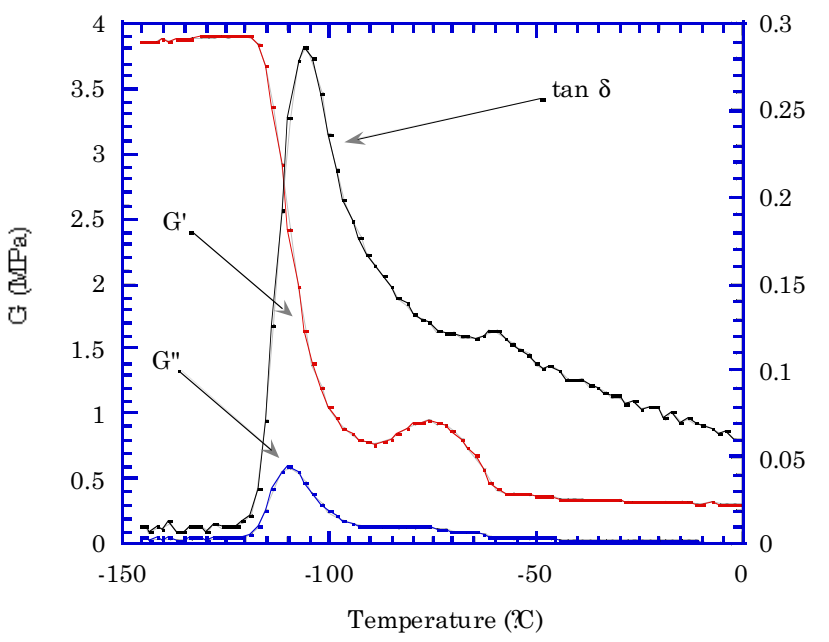

Figure 3. DMA of M97 showing G', G", and $\tan \delta$ as a function of temperature

Since there are two possible components that can crystallize in the filled polymer composite, the dimethyldiphenyl copolymer and the ethoxy-endblocked short chain siloxane processing aid, the individual components of the system were examined separately by DSC. An unfilled M97 polymer exhibited no signs of cold crystallization or melting and a glass transition was the only feature observed at $-120^{\circ} \mathrm{C}$. However, the ethoxyendblocked siloxane processing aid exhibited crystallization at $-95^{\circ} \mathrm{C}$ and melting at $-70^{\circ} \mathrm{C}$ as seen in Fig. 4. Since the role of the ethoxy-endblocked siloxane processing aid is to increase workability during mixing of the filler and polymer, it is expected that the processing aid adsorbs onto the silica filler surfaces. The resulting reaction between the ethoxyendblocked siloxane processing aid and the silica filler during mixing results in the elimination of ethanol which is readily detectable by its odor. DSC examination of the processing aid/silica filler mixture, shown in Fig. 4, did not exhibit any crystallization, melting, or glass transition due to adsorption of the short chain siloxane on the filler surface. Thus, the data eliminate any contribution of the processing aid on the crystallization of the filled M97 polymer samples.

Since the individual components of the polymer composite do not exhibit the same crystallization behavior as the composite, the kinetics of crystallization were examined to determine if combining all the components affected the crystallization rates.

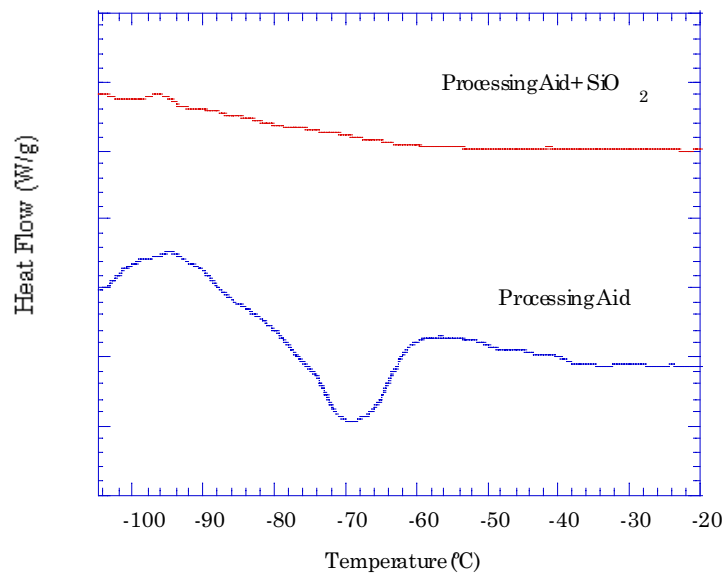

FIGURE 4. DSC of the processing aid and a processing aid $/ \mathrm{SiO}_{2}$ mixture. 
To examine the kinetics of polymer crystallization, isothermal DMA experiments, shown in Figures 5\&6, were performed. These experiments involved rapidly cooling filled and unfilled fully dense samples to $-85^{\circ} \mathrm{C}$ and tracking $\mathrm{G}$ ' as a function of time. The filled system showed that crystallization took place over a 1.8 hour period as evidenced by the increase in G' from 2.2 MPa to a plateau of $6.4 \mathrm{MPa}$ in this time period. Crystallization began after a 45-minute induction period, presumably due to a nucleation effect. Without the filler present, as shown in Figure 6, crystallization took 2.8 hours to fully crystallize with G' increasing from 0.1 $\mathrm{MPa}$ to a plateau of $5.5 \mathrm{MPa}$; this increase in crystallization period was mainly due to an increase in the induction time to 90 minutes. In both filled and unfilled systems, the sharp increase in shear modulus due to crystallization took place over a 1 hour period. This result is contrary to both Andrianov and Chistov's work where crystallization was no longer observed with DSC or XRD after phenyl contents of $8 \mathrm{~mol} \%$. In our work, the presence of the silica filler was shown to increase the rate of crystallization compared to that seen in the unfilled system, which is likely due to the silica filler surfaces acting as heterogeneous nucleation sites.

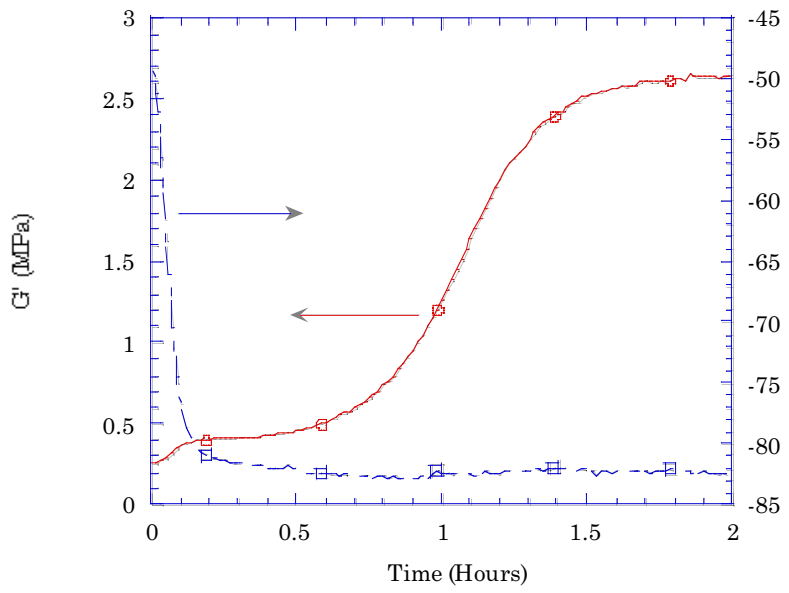

FIGURE 5. DMA at $-85^{\circ} \mathrm{C}$ of M97 showing crystallization time to be approximately 1.8 hours.

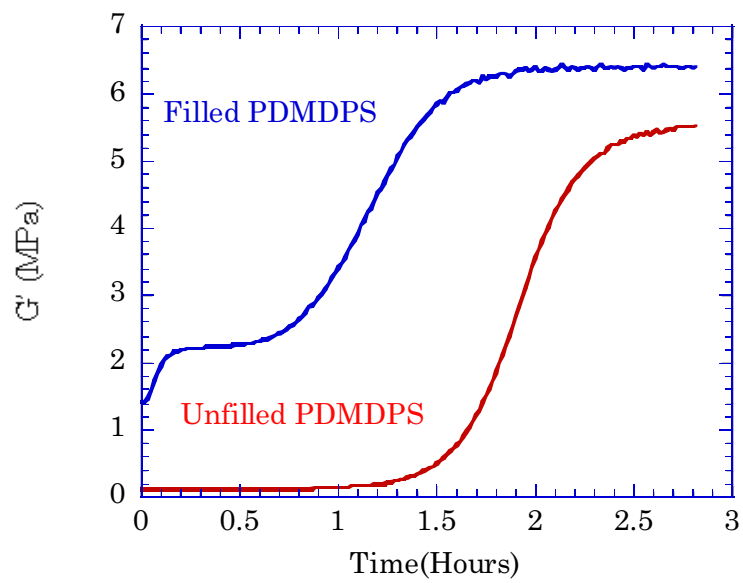

FigURE 6. Isothermal DMA at $-85{ }^{\circ} \mathrm{C}$ of fully dense, unfilled and silica-filled M97 polymer showing the difference in incubation and overall crystallization times.

With the inclusion of a 2 hour isothermal dwell at $-83^{\circ} \mathrm{C}$ during the cooling cycle, in order to allow crystallization to occur to its maximum extent during DSC analysis, a new second melting peak at $-75^{\circ} \mathrm{C}$ was revealed and the amount of melting at $-60^{\circ} \mathrm{C}$ increased, as shown in Figure 7. Cold crystallization is no longer evident in these samples as adequate time has been given to crystallize the polymer during the cool down cycle. In addition, the glass transition has broadened out considerably. It is interesting to compare M97 versus pure PDMS, with regard to the effects of the isothermal dwell (Fig. 7). In PDMS, the dwell during the cooling cycle at crystallization temperatures resulted in a singular melting peak at $-47^{\circ} \mathrm{C}$ compared to the dual melting peaks at $-38^{\circ} \mathrm{C}$ and $-51^{\circ} \mathrm{C}$ observed in Fig. 2 when no dwell was included during the cool down period. The dual melting peaks are proposed to be the result of partial crystallization that occurs during both the cooling and heating cycles due to ramp rate effects. This dual melting phenomenon is reduced to a single melting event with the inclusion of the dwell during the cool down period, as adequate time has been allowed for crystallization to occur to completion in a single event. The M97 polymer, however, 
exhibits two melting peaks where there was only one without the dwell step. Since M97 takes longer to crystallize as compared to PDMS, the dwell was necessary to induce as much crystallization as possible; if not enough time was allowed, very little crystallinity would be observed with this DSC technique. The dual melting phenomenon above could also be evidence that two different crystalline domain types exist in the M97 copolymer due to different molecular weight runs of PDMS.

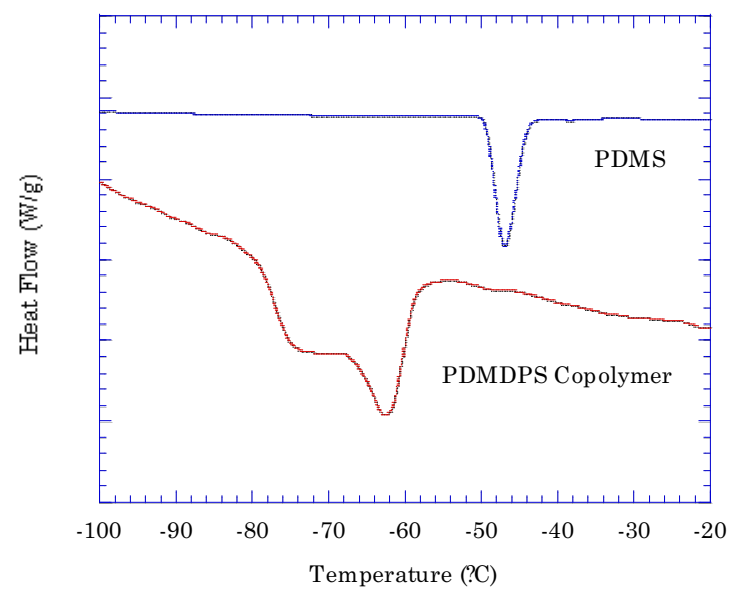

FIGURE 7. DSC of PDMS and M97 base polymer (PDMDPS) with the 2 hour dwell included.

Figure 8 describes a series of isothermal DMA examinations of silica filled M97 irradiated to different gamma doses. These results suggest that the ultimate amount of crystallization does not change with exposure to radiation; rather, it occurs to the same extent only at slower rates. For an unirradiated sample, approximately 1.8 hours were required for full crystallization, while a sample dosed to 25 Mrads took 10 hours to crystallize to the same extent. Like the air-irradiated samples shown in Figure 9, vacuum irradiated samples also do not show a decrease in the amount of crystallization. However, even longer times for crystallization have been observed for the vacuum irradiated samples; this is likely due to increased crosslinking during irradiation.

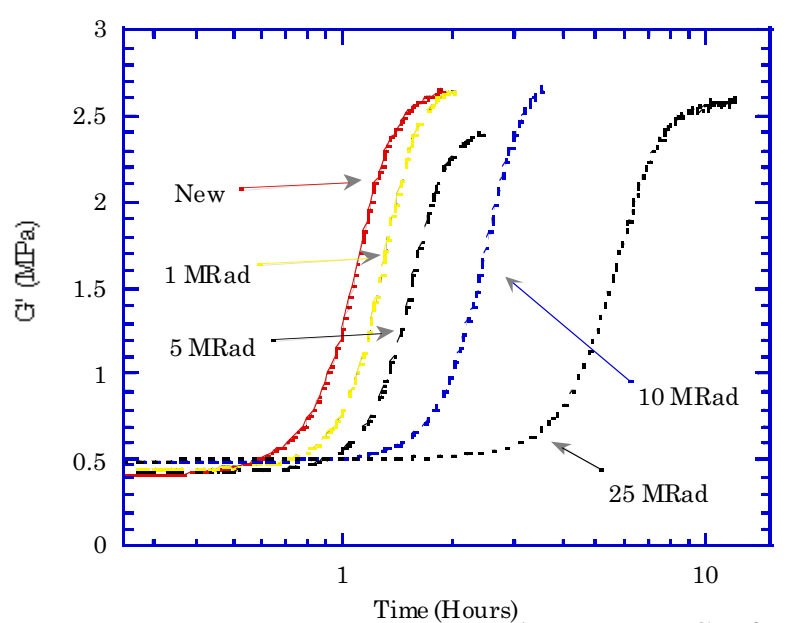

FIGURE 8. Isothermal DMA at $-85^{\circ} \mathrm{C}$ of M97 irradiated under air demonstrating the difference in crystallization time with increasing dose.

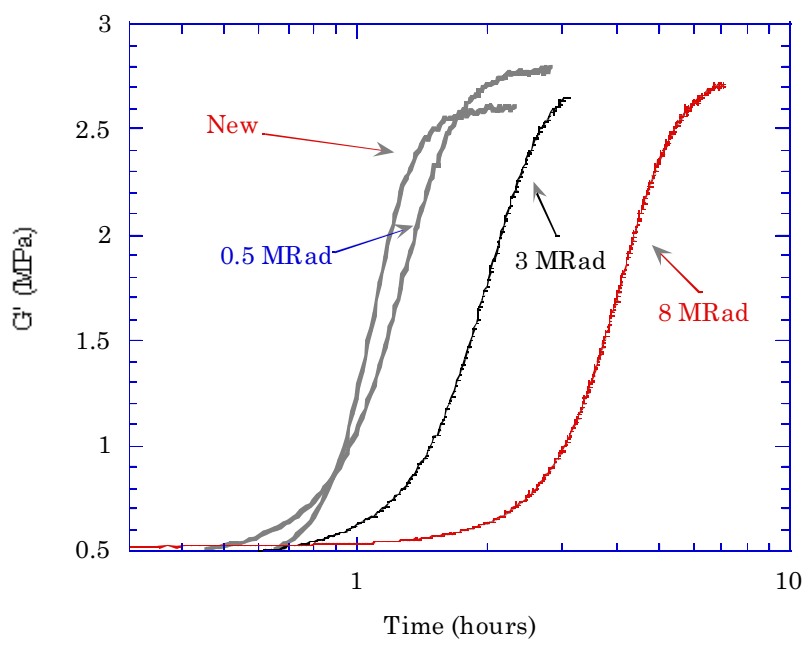

FIGURE 9. Isothermal DMA at $-85^{\circ} \mathrm{C}$ of M97 irradiated under vacuum demonstrating the difference in crystallization time with increasing dose.

The kinetics of shear modulus increase due to isothermal crystallization is identical in form to overall crystallization measured by more direct techniques. The crystallization kinetic behavior is commonly described using the Avrami relationship ${ }^{12}$ and a similar form was applied to the shear storage modulus data. To account for the increase in modulus from an initial to final value, the following modified Avrami relationship was used:

$$
G^{\prime}(t)=G_{f}^{\prime}+\left(G_{i}^{\prime}-G_{f}^{\prime}\right) e^{-k t^{n}}
$$


where $G_{i}^{\prime}$ is the initial modulus, $G_{f}^{\prime}$ the final modulus and $k$ and $n$ are the typical Avrami parameters. The values of these parameters obtained from a fit of (1) to the data for filled M97 exposed to different $\gamma$ radiation levels are summarized in Table 1. They show that the initial and final moduli as well as the exponent $n$ are relatively constant for all levels of exposure. Furthermore, if it is assumed that the modulus change is directly proportional to the level of crystallinity, then the value of 4 found for the exponent is indicative of homogeneous nucleation and spherulitic growth ${ }^{13}$. The only significant effect of radiation exposure is on the rate of crystallization, which is captured by the parameter $k$.. A common way of indicating crystallization rates is to measure the inverse of the time to reach half the maximum value. From (1), this time is given by

$$
t_{1 / 2}=\left[\frac{\ln 2}{k}\right]^{1 / n}
$$

Values for the inverse of this time are plotted against radiation dose level in Figure 10, clearly showing the effect of radiation to retard crystallization rate and the difference between material exposed in vacuum and air environments.
TABLE 1. Avrami parameters for kinetics of shear modulus increase at $-85^{\circ} \mathrm{C}$.

\begin{tabular}{|c|c|c|c|c|}
\hline $\begin{array}{c}\text { Exposure } \\
(\mathrm{MRad})\end{array}$ & $\begin{array}{c}G_{i}^{\prime} \\
(\mathrm{MPa})\end{array}$ & $\begin{array}{c}G_{f}^{\prime} \\
(\mathrm{MPa})\end{array}$ & $n$ & $k$ \\
\hline \hline None & .429 & 2.58 & 4.13 & 1.681 \\
\hline \hline .5 in Air & .472 & 2.74 & 4.41 & 1.467 \\
\hline 1 in Air & .450 & 2.62 & 4.69 & .548 \\
\hline 3 in Air & .445 & 2.41 & 4.89 & .163 \\
\hline 5 in Air & .433 & 2.36 & 4.75 & .208 \\
\hline 10 in Air & .495 & 2.64 & 4.67 & .021 \\
\hline 25 in Air & .500 & 2.55 & 4.09 & $7.78 \mathrm{E}-4$ \\
\hline \hline .5 in Vac. & .480 & 2.76 & 3.41 & .573 \\
\hline 3 in Vac. & .490 & 2.67 & 3.49 & .108 \\
\hline 8 in Vac. & .529 & 2.69 & 3.78 & $5.04 \mathrm{E}-3$ \\
\hline \hline
\end{tabular}

Although the use of aromatic side groups in polymers has been shown to increase the polymer's radiation resistance due to its delocalized $\pi$-electron structure, crosslinking has been shown to occur. ${ }^{14,15}$ As seen in Figure 11, a corresponding change in G' upon irradiation can be seen, due to increased crosslinking. Although the current results indicate that the crosslink density of an irradiated polymer increases with dose, this apparently has no effect on the ultimate amount of crystallinity that occurs. 


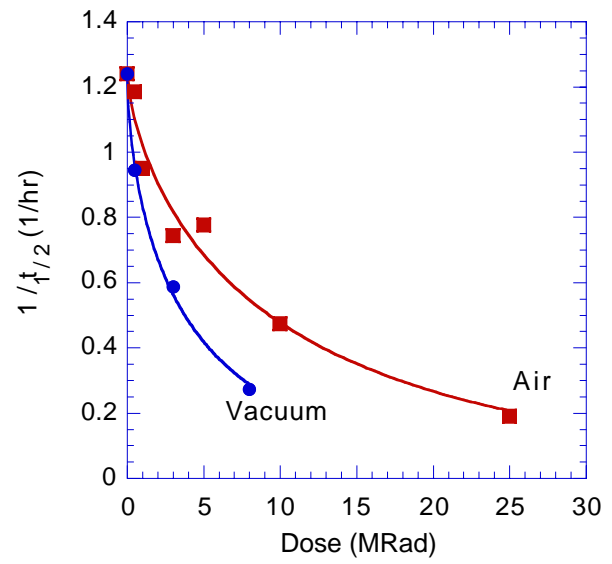

FIGURE 10. Rate of modulus increase versus level of radiation exposure.

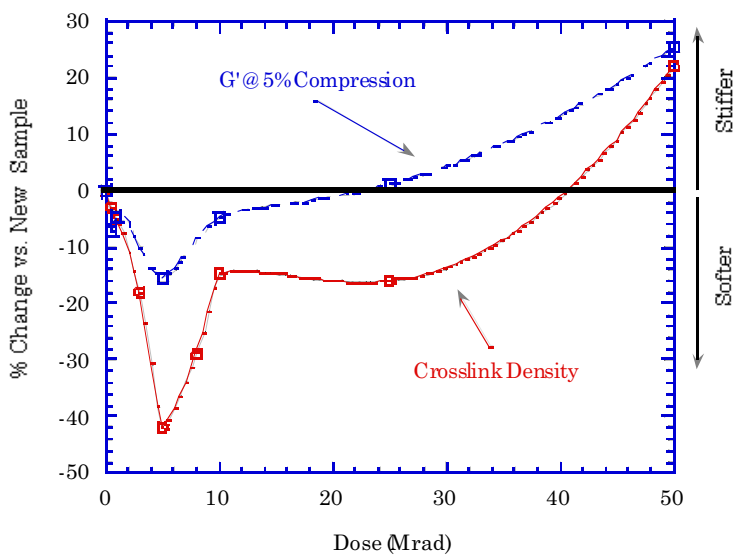

Figure 11. Crosslink Density and G' vs. dose for M97 showing the corresponding changes with $\gamma$-irradiation.

It is unknown at this time exactly where additional crosslinking during irradiation occurs along the siloxane polymer backbone. If crosslinking occurs across dimethyl groups, then the extent of crystallinity should decrease with dose. On the other hand, if irradiation-induced crosslinking occurs across the diphenyl groups, then the extent of crystallinity may not necessarily be affected. Given that the ultimate extent of crystallinity is unchanged upon irradiation, it is likely that the crystallization is occurring in the diphenyl regions of the M97 base polymer.

\section{SUMMARY}

MDSC and DMA techniques were used to show that silica filled and unfilled M97 composites exhibit cold crystallization at $80^{\circ} \mathrm{C}$. Isothermal DMA analysis shows that crystallization takes place over a period of 1.8 hours; the time to reach the maximum extent of crystallinity increases with $\gamma$-irradiation, primarily due to an increase in the induction/nucleation period before crystallization occurs. However, the ultimate amount of crystallization does not decrease with increasing radiation dose although crosslink density has been shown to increase with dose. It is postulated that this is due to the crosslinking occurring in the noncrystallizing portion phenyl-containing regions of the polymer. Unfilled copolymer systems are shown to take longer for crystallization to be initiated, presumably due to a lack of the heterogeneous nucleation sites provided by the filler surfaces.

\section{ACKNOWLEDGEMENTS}

This work was performed under the auspices of the U.S. Department of Energy by the Lawrence Livermore National Laboratory under contract \# W-7405ENG-48. The authors would like to thank Chris Trapp (LLNL) and Frank Balgos (LLNL) for performing the $\gamma$-irradiations, Albert Shields (LLNL) for performing DMA testing, and Aaron May (Honeywell $\mathrm{KCP}$ ) for DSC testing.

\section{REFERENCES}

${ }^{1} \mathrm{~J}$. Cowie, "Polymers: Chemistry and Physics of Modern Materials", p. 235, Chapman and Hall, New York, 1991.

2 K. Andrianov, G. Slonimskii, A. Zhdanov, V. Levin, Y. Godovakii, and V. Moskalenko, J. Poly. Sci. A, 10, 1 (1972).

${ }^{3}$ M. Aranguren, Polymer, 39, 4897 (1998). 
${ }^{4}$ A. Yim and L. St. Pierre, Poly. Lett., 8, 241 (1970).

${ }^{5}$ K. Andrianov, G. Slonimskii, A. Zhdanov, V. Levin, Y. Godovakii, and V. Moskalenko, J. Poly. Sci. A, 10, 13 (1972).

6 S. Chistov, O. Levina, N. Lebedeva, and I. Skorokhodov, Poly. Sci. U.S.S.R., 26, 2911 (1984)

7 A. T. Chien, R. Maxwell, D. Chambers, B. Balazs, and J. D. LeMay, LLNL UCRLJC-136064.

8 M. Koike and A. Danno, J. Phys. Soc. Japan, 15, 1501 (1960).

9 M. Koike, J. Phys. Soc. Japan, 18, 387 (1963).

10 C. Delides, Rad. Phys. Chem., 16, 345 (1980).

11 J. O'Donnell and D. Sangster, Principles of Radiation Chemistry, Edward Arnold Publishers Ltd., London (1970).

${ }^{12}$ M. Avrami, J. Chem. Phys., 7, 1103

(1939).

13 J. M. Schultz, "Polymer Materials Science," pg. 385, Prentice-Hall, Inc., Englewood Cliffs, New Jersey, 1974.

14 D. Fisher, J. Zack, and E. Warrick, Lubrication Eng., 15, 407 (1959).

15 W. Burlant, J. Neerman, and V. Serment, J. Poly. Sci., 58, 491 (1962). 